\title{
Microstructural Evaluation on Shape Recovery in Stainless Fe-Mn-Si-Cr-Ni-Co SMA Processed by Wire Drawing
}

\author{
Elaine Cristina Andrade ${ }^{\mathrm{a} *}$, Heide Heloise Bernardi ${ }^{\mathrm{a}, \mathrm{b}}$, Jorge Otubo $^{\mathrm{a}}$ \\ anstituto Tecnológico de Aeronáutica - ITA, São José dos Campos, SP, Brasil \\ ${ }^{\mathrm{b}}$ Faculdade Tecnológica de São José dos Campos - FATEC, \\ Prof. Jessen Vidal, São José dos Campos, SP, Brasil
}

Received: June 5, 2013; Revised: March 27, 2014

\begin{abstract}
The effect of the microstructure on the shape recovery in stainless $\mathrm{Fe}-8 \mathrm{Mn}-5 \mathrm{Si}-13 \mathrm{Cr}-6 \mathrm{Ni}-12 \mathrm{Co}$ shape memory steel (SSMS) was evaluated using tensile tests and reversion temperature of $600^{\circ} \mathrm{C}$ for a pre-strain of $4 \%$. The tests were performed for a solution treated and annealed conditions at different temperatures after wire drawing of $57 \%$ area reduction. The best total shape recovery (TSR) was $83 \%$ for a sample deformed and annealed at $850^{\circ} \mathrm{C}$. It was concluded that the elastic (or, superelastic) shape recovery (ESR) is high when the austenitic matrix strength is high surpassing the value of shape recovery due to memory effect (SR) and once the austenitic matrix becomes softer, the contribution of SR increases and that of ESR decreases.
\end{abstract}

Keywords: Stainless Shape Memory Steel (SSMS), wire drawing, microstructure, elastic shape recovery, memory shape recovery

\section{Introduction}

The addition of some alloying elements in Fe-Mn-Si based alloys resulted in stainless shape memory steels (SSMS), especially in stainless Fe-Mn-Si-Cr-Ni-Co shape memory steel. These steels have the capacity to recover its original shape by the reverse transformation of stress induced $\varepsilon$ martensite ${ }^{1-4}$. Some factors that influence in the capacity of shape memory recovery have been studied, such as the amount of pre-strain, thermomechanical training, alloying elements, deformation temperature and annealing temperature ${ }^{5-12}$.

According to Akhondzadeh et al..$^{5}$, the annealing temperature is the more effective parameter to control the shape memory effect due to microstructural changes developed in the parent phase, influencing directly the reverse martensitic transformation. Usually, for iron based shape memory alloy, the shape recovery (SR) presented in the literature is related to the total shape recovery (TSR) and no mention to the elastic shape recovery (ESR) or superelastic shape recovery (SESR) is done $\mathrm{e}^{5-10}$. As shown by Otubo et al. ${ }^{11}$, for a similar alloy with no cobalt addition, in a solution treated condition, the major contribution to TSR comes from shape recovery (SR) due to shape memory effect on heating. The contribution due to elastic shape recovery (ESR) was constant and well lower than that of memory effect. The authors attributed these results to a low strength of austenitic matrix with a microstructure free of complex defects and consisting of equiaxed grains. Recently, Kafer et al. ${ }^{12}$ studied the effect of severe plastic deformation (introduced by ECAE processing) and heat treatment on stainless $\mathrm{Fe}-\mathrm{Mn}-\mathrm{Cr}-\mathrm{Ni}-\mathrm{Co}-\mathrm{Ti}$ shape memory steel, separated the TSR in two parts as ESR and SR

*e-mail: elaine_femat@hotmail.com concluding that while the matrix hardness is low the major contribution to TSR comes from SR on heating as shown previously by Otubo et al. ${ }^{11}$ and as the matrix hardness starts to increase, the shape recovery due to ESR also starts to increase surpassing the SR. In order to evaluate the effect of microstructure on the total shape recovery (TSR), elastic shape recovery (ESR) and shape recovery (SR) on heating, stainless Fe-8Mn-5Si-13Cr-6Ni-12Co shape memory steel was processed by wire drawing and heat treatment.

\section{Experimental}

Stainless Fe-8Mn-5Si-13Cr-6Ni-12Co (\%wt.) shape memory steel (SSMS) used in this work was produced by vacuum induction melting. The $65 \times 65 \mathrm{~mm}^{2}$ ingots was hot forged and then hot rolled down to $6.75 \mathrm{~mm}$ in diameter, and then cold drawn to a wire of $2.38 \mathrm{~mm}$ in diameter. At this diameter, the wire was solution treated at $1050^{\circ} \mathrm{C}$ for 30 minutes, quenched in water room temperature and then cold drawn to a wire of $1.55 \mathrm{~mm}$ in diameter wire resulting in $57 \%$ of area reduction (AR). The deformed samples $(\mathrm{AR}=57 \%)$ were annealed at temperatures ranging from $350^{\circ} \mathrm{C}$ to $1050^{\circ} \mathrm{C}$ for 1 hour and cooled in air. The same heat treatments were duplicated for a solution treated samples to serve as a reference.

The microstructural characterization was performed using a Carl Zeiss CCD: SH318 optical microscope (OM) and a Hitachi (TM 3000) scanning electron microscope (SEM) equipped with an energy dispersive spectrometer (EDS) system. Vickers hardness testing was performed using a Future-Tech FM-7000 microindenter with a load of $200 \mathrm{~g} / 10 \mathrm{~s}$. The micrograph analyses and the Vickers hardness 
were undertaken in longitudinal section of the samples (wire drawing direction). The constituent phases in the solution treated and deformed and annealed at $850^{\circ} \mathrm{C}$ samples were

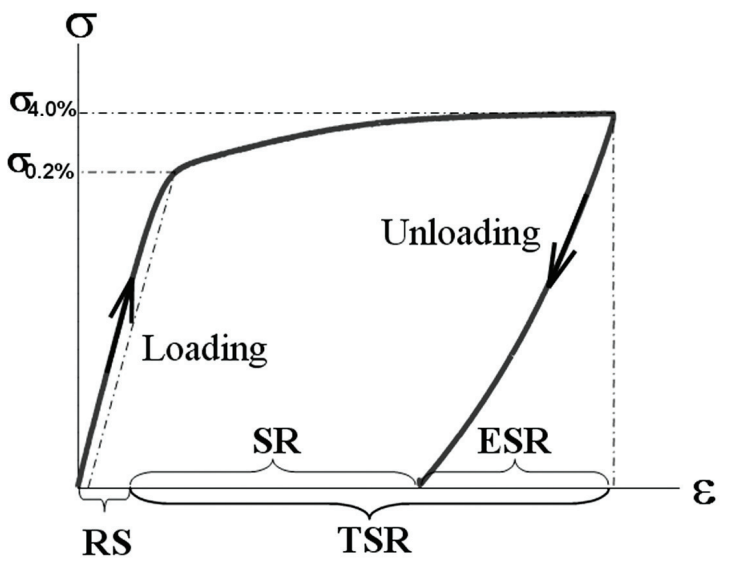

Figure 1. Schematic of the tensile test for measuring the shape recovery. The parameters are as follow: TSR (Total Shape Recovery) $=$ ESR (Elastic Shape Recovery) + SR (Shape Recovery upon heating) and RS (Residual Strain).

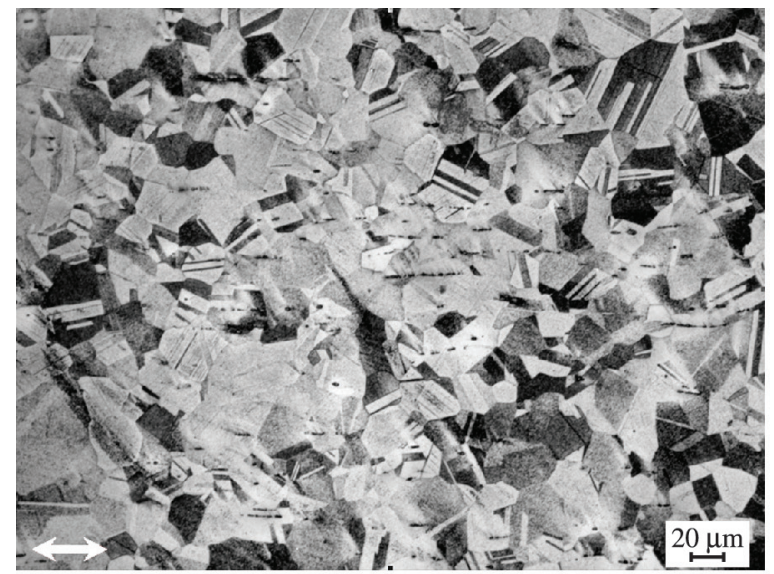

(a)



(c) determined by a Rigaku Multiflex X-ray diffractometer, using $\mathrm{Cu} \mathrm{K} \alpha$ radiation.

The shape memory capacity was analyzed by tensile testing using an Instron 5500R machine. Figure 1 shows a schematic of the tensile test. The wire specimens of $50 \mathrm{~mm}$ length and of $1.55 \mathrm{~mm}$ in diameter, were pre-strained by $4 \%,\left(\sigma_{4,0 \%}\right)$, at room temperature and then unloaded down to zero stress. The amount of elastic shape recovery (ESR) was calculated by difference between the lengths of the specimens before loading and unloaded states. Whereas, the amount of shape recovery due to memory effect (SR) was determined after heating the unloaded specimens at reversion temperature of $600^{\circ} \mathrm{C}$ for 30 minutes, followed by a water-quenching. The total shape recovery (TSR) was estimated as TSR $=\mathrm{ESR}+\mathrm{SR}$. The parameter $\mathrm{RS}$ is residual strain upon shape recovery heating.

\section{Result and Discussion}

The Figure 2 shows the microstructure of the stainless Fe-Mn-Si-Cr-Ni-Co shape memory steel at different conditions. In the solution treated condition (Figure 2a) the microstructure is essentially composed by equiaxed grains of austenite $(\gamma)$, thermally induced martensite plates

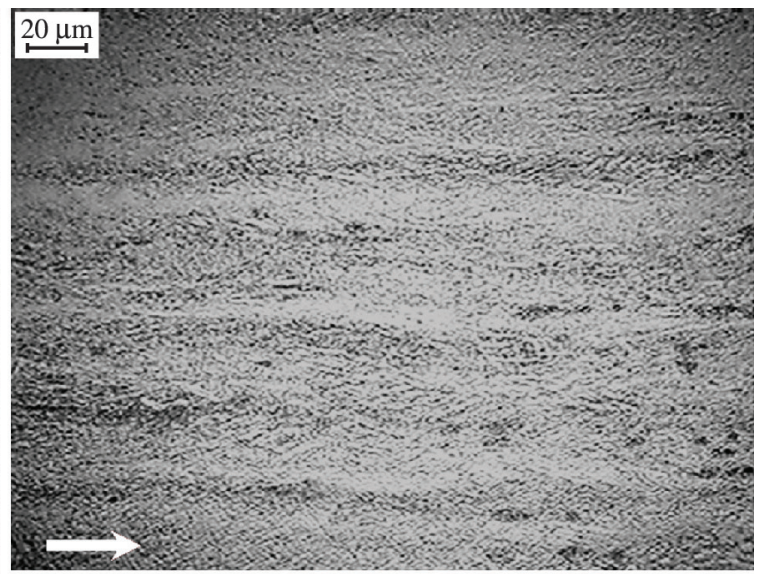

(b)

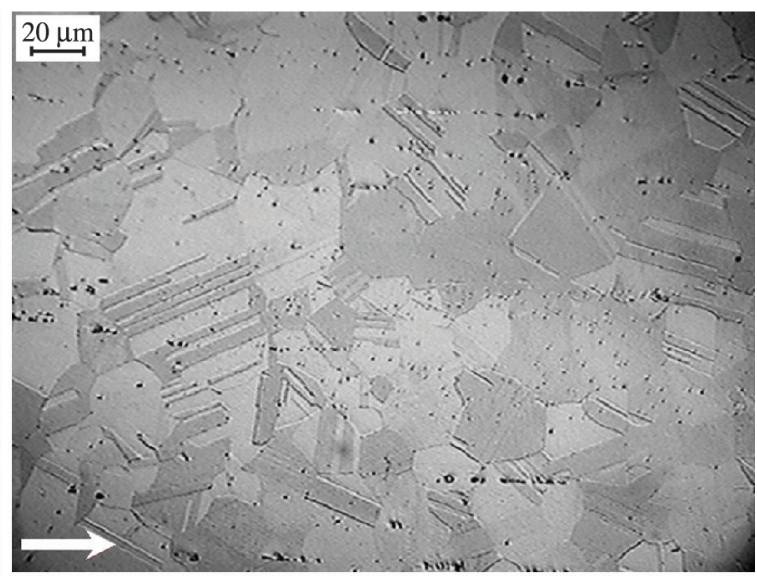

(d)

Figure 2. The optical micrographs of specimens in different conditions: (a) solution treated, and deformed and annealed at (b) $750^{\circ} \mathrm{C}$ for $1 \mathrm{~h}$, (c) $850^{\circ} \mathrm{C}$ for $1 \mathrm{~h}$ and (d) $950^{\circ} \mathrm{C}$ for $1 \mathrm{~h}$. 
( $\varepsilon$ ) and annealing twins, which are characteristic defects of these stainless steels with a low stacking fault energy $(\mathrm{SFE})^{1}$. The effects of annealing temperature on the drawn wire with $57 \%$ of area reduction are shown in Figures $2 \mathrm{~b}$, $2 \mathrm{c}$ and $2 \mathrm{~d}$. The Figure $2 \mathrm{~b}$ show the microstructure of the sample annealed at $750^{\circ} \mathrm{C}$ for $1 \mathrm{~h}$. It is observed a texture in the drawing direction (indicated by white arrow). No significant microstructural change is observed compared as drawn wire (not shown). The annealing at $750^{\circ} \mathrm{C}$ was not enough to eliminate crystallographic defects created during cold drawing. It has been reported ${ }^{3,4}$ that these complex defects varied with the annealing conditions and studies have indicated that the volume fractions of these defects were high when the annealing temperature was low. Figure 2c shows the microstructure after annealing at $850^{\circ} \mathrm{C}$ for $1 \mathrm{~h}$. In this condition the texture due to wire drawing disappeared, but the grain boundaries still are difficult to be seen due to second phase precipitates. The EDS analysis revealed that these precipitates were enriched in $\mathrm{Cr}$ and $\mathrm{Si}$ (indicated by white circles in Figure 2c). Annealing at $950^{\circ} \mathrm{C}$ (Figure 2d) promoted the recrystallization and dissolution of second phase particles returning to initial solution treated condition, with equiaxed grains and some annealing twins.

The Figure 3 shows the X-Ray diffraction (XRD) spectras of the solution treated, then deformed and annealed at $850^{\circ} \mathrm{C}$ sample compared to just solution treated sample. The solution treated sample indicates the presence of austenite $(\gamma)$ and martensite $(\varepsilon)$ in the microstructure. On the other hand, the deformed and annealed sample showed the occurrence of news peaks, besides the existence of $\gamma$ and $\varepsilon$ phases. The appearance of these news peaks could be related to a second phase precipitates rich in $\mathrm{Cr}$ and $\mathrm{Si}$ as detected by EDS analysis.

The Figure 4 shows the hardness variation as a function of heat treatment temperature for solution treated samples (black square dots) and for samples that suffered a 57\% area reduction after solution heat treatment (black open cycle dots). For solution treated samples no hardness variation could be seen for all the heat treatment temperatures $\left(350^{\circ} \mathrm{C}\right.$ to $\left.1050^{\circ} \mathrm{C}\right)$. The average hardness value was about $230 \mathrm{HV}$. The effect of work hardening can be seen through the hardness that jumped from about $230 \mathrm{HV}$ for a solution treated state to more than $450 \mathrm{HV}$ after $57 \%$ area reduction, that is, an increase of about $220 \mathrm{HV}$, that is, almost double value. The annealing effect after wire drawing can be seen following the hardness values that were about $550 \mathrm{HV}$ at $350^{\circ} \mathrm{C}$ reaching their maximum of about $640 \mathrm{HV}$ at $550^{\circ} \mathrm{C}$ and then decreasing for higher annealing temperature. At $950^{\circ} \mathrm{C}$ the hardness value is practically the value presented by solution treated sample and at $1050^{\circ} \mathrm{C}$ the hardness value coincides with solution treated returning to initial state.

The increase in the hardness of drawn wire specimens followed by heat treatments is attributed not only to work hardening due to deformation, but also to the precipitation of second phase particles rich in $\mathrm{Cr}$ and $\mathrm{Si}$ as seen by EDS analysis and the appearance of new peaks in XRD pattern. The hardness values demonstrate that the nucleation of this second phase particle started at lower heat treatments temperatures, let say at $350^{\circ} \mathrm{C}$ and at $850^{\circ} \mathrm{C}$ occurred the coalescence of those precipitates (Figure 2c). As shown

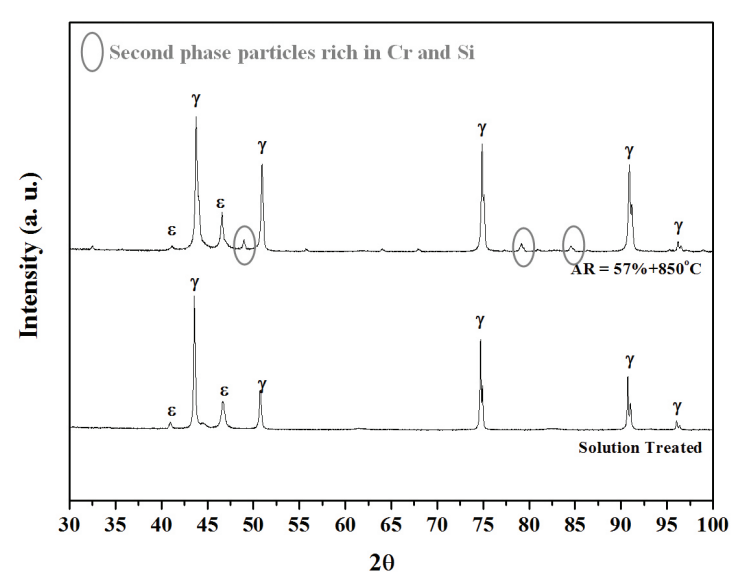

Figure 3. XRD patterns of the stainless shape memory steel in the solution treated and deformed $(\mathrm{AR}=57 \%)$ and annealed at $850^{\circ} \mathrm{C}$ for $1 \mathrm{~h}$ conditions.

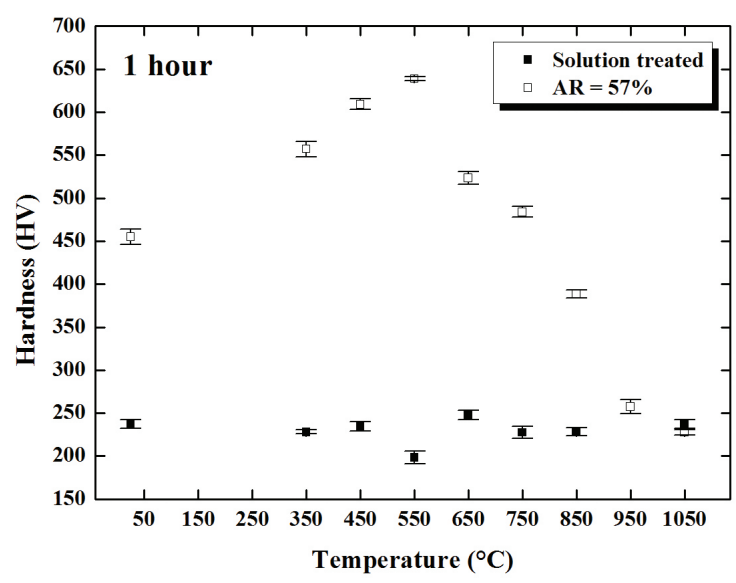

Figure 4. Effect of the annealed on the hardness for different conditions: solution treated and deformed with $57 \%$ of area reduction.

above, no heat treatment influence could be seen on the hardness of solution treated samples. Therefore, the variation is attributed to a synergic effect of wire drawing and appropriate heat treatment temperature promoting the precipitation of second phase particles. The XRD analysis (Figure 3 ) corroborated with these results, showing that only $\gamma$ and $\varepsilon$ phases were presents in a solution treated samples and new peaks appeared after cold drawing and heat treatment. Summarizing, the softening observed for sample deformed and annealed at $650^{\circ} \mathrm{C}$ could be attributed to the beginning of decrease of crystallographic defects although deformation texture could be seen even after annealing at $750^{\circ} \mathrm{C}$ (Figure $2 \mathrm{~b}$ ) and at $850^{\circ} \mathrm{C}$ (Figure 2c) one can see a spherodized particles indicating coalescence and therefore justifying the hardness decrease. At $950^{\circ} \mathrm{C}$ the sample is completely recrystallized returning to solution treated state (Figure 2d).

In Figure 5 it is shown the effect of microstructure on the shape recovery capacity of stainless $\mathrm{Fe}-\mathrm{Mn}-\mathrm{Si}-\mathrm{Cr}$ Ni-Co shape memory steel. The contributions of elastic 


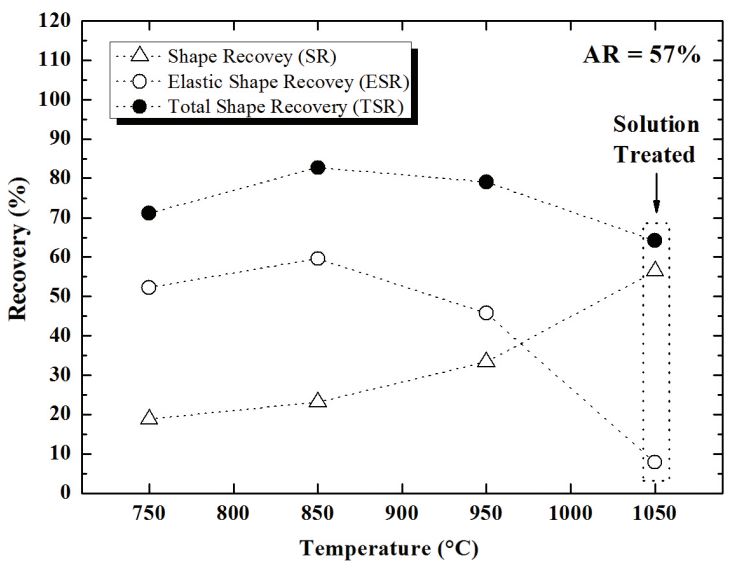

Figure 5. Elastic Shape Recovery (ER), Shape Recovery (SR) and Total Shape Recovery (TSR) as a function of annealing temperature.

shape recovery (ESR) and shape recovery due to memory effect (SR) on the total shape recovery (TSR) are clearly seen. While the austenitic matrix hardness (therefore the mechanical strength) is high, the contribution of ESR exceeds that of SR. These results showed that the ESR is related to austenitic matrix strengthening. This parameter is higher when the annealing is performed in low temperatures, in which complex defects promoted during the deformation were not fully eliminated, as well the precipitate particles. Increasing the annealing temperature to $950^{\circ} \mathrm{C}$, the ESR contribution to TSR decreases and the shape recovery due memory effect, SR increases approaching each other. In a solution treated condition, that is, at $1050^{\circ} \mathrm{C}$ annealing, the major contribution comes from SR and contribution of ESR to TSR is minimum. The best shape recovery is observed for the sample annealed at $850^{\circ} \mathrm{C}$ with a TRS of $83 \%$ for a pre-strain of $4 \%$. This result suggests that the microstructure essentially composed of an austenitic matrix and precipitates rich in $\mathrm{Cr}$ and $\mathrm{Si}$ (Figure 2c), was beneficial for stress induced formation of $\varepsilon$ martensite and its reversion to austenite $(\gamma)$. This result is better than the shape recovery presented by others authors ${ }^{5,11}$ that obtained the same value only after training cycles. Maji et al. ${ }^{10}$ have shown that the better shape recovery for stainless $\mathrm{Fe}-\mathrm{Mn}-\mathrm{Si}-\mathrm{Cr}-\mathrm{Ni}$ shape memory steel was obtained when the austenitic matrix contained $\mathrm{Fe}_{5} \mathrm{Ni}_{3} \mathrm{Si}_{2}$ type intermetallic phase precipitated at grain boundaries.

\section{References}

1. Inagaki H. Shape memory effect of $\mathrm{Fe}-14 \% \mathrm{Mn}-$ $6 \% \mathrm{Si}-9 \% \mathrm{Cr}-6 \% \mathrm{Ni}$ alloy polycrystals. Zeitschrift für Metallkunde. 1992; 83:90-96.

2. Yang JH, Chen H and Wayman CM. Development of iron based shape memory alloys associated with FCC to HCP martensitic transformations: Part I. Shape memory behavior. Metallurgical Transactions A. 1992; 23:1431-1437. http://dx.doi.org/10.1007/ BF02647326
Finally is worth to state that when analyzing the TSR, the contribution of the elastic part (ESR) and shape recovery due memory effect (SR) should be taken into account. The first is high when a austenitic matrix strength is high such as for low temperature annealing and it decreases as the matrix become softer prevailing the shape recovery due to memory effect, that is, the reverse movement of Shockley partial dislocations $\varepsilon(\mathrm{HC}) \leftrightarrow \gamma(\mathrm{CFC})$ is facilitated or, the movement of martensite-martensite and austenite-martensite interfaces would be facilitated in structures with little defects as the solution treated samples. The correlation to the movement of perfect dislocation is valid. Cleaner the matrix, easier is the movement of perfect dislocation and vice-versa.

\section{Conclusion}

1 The deformation by wire drawing after appropriate heat treatment promoted the precipitation of the second phase particles rich in $\mathrm{Cr}$ and $\mathrm{Si}$. At $850^{\circ} \mathrm{C}$, occurred the coalescence of these precipitates and at $950^{\circ} \mathrm{C}$ it were practically dissolved with recrystallized microstructure, similar to the solution treated condition;

2 The hardness increased significantly with the deformation of stainless steel $(\mathrm{AR}=57 \%)$ due to cumulative effect of work hardening and precipitation of the second phase particles. The maximum value obtained was of $640 \mathrm{HV}$ after annealing at $550^{\circ} \mathrm{C}$;

3 The better total shape recovery (TSR) of $83 \%$ was obtained for a sample annealed at $850^{\circ} \mathrm{C}$;

4 The total shape recovery (TSR) is composed by two parts: elastic shape recovery (ESR) and shape recovery due to memory effect upon heating (SR). The ESR is high when the austenitic matrix hardness is high surpassing the value of SR. As the austenitic matrix becomes softer, the contribution of SR increase and that of ESR decrease. In a "clean" solution treated state, the major contribution comes from SR.

\section{Acknowledgements}

The authors wish to thank FAPESP, CAPES, CNPq Universal (476030/2011-0), CNPq/Casadinho/PROCAD (552199/2011-70) - UFCG/UFRJ/ITA, PRO-INFRA 2012 e 2013, IEAv, IPEN, AEB and Villares Metals S. A. for supporting the ITASMART (ITA Shape Memory Alloys Research and Technology Group).

3. Yang JH, Chen H and Wayman CM. Development of iron based shape memory alloys associated with FCC to HCP martensitic transformations: Part II. Transformation behavior. Metallurgical Transactions A. 1992; 23:1439-1444. http:// dx.doi.org/10.1007/BF02647327

4. Yang JH, Chen H and Wayman CM. Development of iron based shape memory alloys associated with FCC to HCP martensitic transformations: Part III. Microstructures. Metallurgical Transactions A. 1992; 23:1445-1454. http://dx.doi.org/10.1007/ BF02647328 
5. Akhondzadeh A, Zangeneh-Madar K and Abbasi SM. Influence of annealing temperature on the shape memory effect of $\mathrm{Fe}-$ $14 \mathrm{Mn}-5 \mathrm{Si}-9 \mathrm{Cr}-5 \mathrm{Ni}$ alloy after training treatment. Materials Science and Engineering A, 2008, 489:267-272. http://dx.doi. org/10.1016/j.msea.2007.12.014

6. Li H, Dunne D and Kennon N. Factors influencing shape memory effect and phase transformation behavior of $\mathrm{Fe}$ Mn-Si based shape memory alloys. Materials Science and Engineering A. 1999; 273-275:517-523. http://dx.doi. org/10.1016/S0921-5093(99)00391-3

7. Gu Q, Humbeek JV and Delaey L. On the improvement of shape memory effect in $\mathrm{Fe}-16 \mathrm{Mn}-5 \mathrm{Si}-9 \mathrm{Cr}-4 \mathrm{Ni}$ alloys by thermomechanical treatment. Scripta Metallurgica et Materialia. 1994; 30 (12):1587-1592. http://dx.doi. org/10.1016/0956-716X(94)90313-1

8. Wang XX and Zhao LC. The effect of thermal-mechanical training on the formation of stress-induced $\varepsilon$ martensite in an Fe-Mn-Si-Ni-Co alloy. Scripta Metallurgica et Materialia. 1992; 26:1451-1456. http://dx.doi. org/10.1016/0956-716X(92)90665-2
9. Wang YQ, Wang Z, Yang JH and Zhao LC. Effect of microstructure of austenite on the shape memory effect in an Fe-Mn-Si-Ni alloy. Scripta Materialia. 1997; 36(7):741-745. http://dx.doi.org/10.1016/S1359-6462(96)00449-6

10. Maji BC and Krishnan M. The effect of microstructure on the shape recovery of a Fe-Mn-Si-Cr-Ni stainless steel shape memory alloy. Scripta Materialia. 2003; 48:71-77. http:// dx.doi.org/10.1016/S1359-6462(02)00348-2

11. Otubo J, Mei PR, Koshimizu S, Shinohara AH and Suzuki CK. Relationship between thermomechanical treatment, microstructure and a' martensite in stainless Fe-based shape memory alloys. Materials Science and Engineering A. 1999; 273-275:533-537. http://dx.doi.org/10.1016/S09215093(99)00394-9

12. Käfer KA, Bernardi HH, Naito LKF, Lima NB and Otubo J. Shape memory properties of ultrafine-grained austenitic stainless. Materials Science Forum. 2013; 738-739:496-500. http://dx.doi.org/10.4028/www.scientific.net/MSF.738739.496 